\title{
Política pública y componentes sociodemográficos de la microempresa en el nuevo siglo: el caso de Colombia y México
}

\section{Public policy and socio-demographic components of the microenterprise in the new century: the case of Colombia and Mexico}

\author{
Fernando Neira-Orjuela*
}

\begin{abstract}
In Latin America two countries have been characterized by receiving important international funds to foster and consolidate microenterprises: Colombia and Mexico. With said supports, both countries have sought to foment employment and social development. In this sense, the present article, which is part of a broader qualitative research on microenterprises in Latin America, has as an objective to analyze the development of microenterprises in both countries and the socio-demographic characteristics of their labor force. For such end, in this research we make a brief historic account of the way and the conditions wherein public policies for the microenterprises appear and evolve in both countries; likewise, some of the sociodemographic characteristics of microenterprises in each country are analyzed.
\end{abstract}

Keywords: microenterprises, socio-demography, entrepreneurial policies, development.

\section{Resumen}

En América Latina dos países se han caracterizado por recibir importantes apoyos internacionales para el fomento y la consolidación de la microempresa: Colombia y México. Con dichos apoyos, ambos países han buscado fomentar el surgimiento e incremento de las microempresas como pilar fundamental del fomento al empleo y el desarrollo social. En este sentido, el presente artículo-que es parte de una investigación cualitativa más amplia sobre la microempresa en América Latina- tiene como objetivo analizar el desarrollo de la microempresa en ambos países y las características sociodemográficas de su fuerza laboral. Para tal fin, en esta investigación se hace un breve recuento histórico de la forma y las condiciones en que surge y evoluciona la política pública hacia la microempresa en ambos países, asimismo, se comparan algunas características sociodemográficas de la microempresa en cada país.

Palabras clave: microempresas, sociodemografía, políticas empresariales, desarrollo.

* Universidad Nacional Autónoma de México, México. Correo-e: ferneira3@yahoo.com.mx. 


\section{Transformaciones de la política hacia la microempresa en Colombia y México}

\subsection{El caso colombiano}

La historia de la aparición de la microempresa en Colombia está fuertemente asociada a las condiciones económicas del país a mediados del siglo pasado. Durante la década de los cincuenta, periodo de posguerra, se dio una gran captación de capitales extranjeros por la industria nacional, lo que contribuyó al surgimiento de las economías de escala, concentración del mercado y plantas con tecnología avanzada (Villegas, 2002). Así, aumentó la fabricación de bienes intermedios y de consumo durable y el país fue ajustando su economía para lo que posteriormente sería el régimen de sustitución de importaciones.

Aunque en las décadas anteriores hubo un importante crecimiento en las pequeñas industrias, en los años sesenta se presentó un estancamiento en el proceso industrial, que sólo se manifestó en la segunda mitad de la década de 1970. En este periodo la misión del Standard Research Institute hizo recomendaciones para el desarrollo de la pequeña y mediana industria en Colombia, por lo que en esta época se empezaron a establecer las primeras políticas de apoyo a las pequeñas y medianas empresas (Villegas, 2002: 80).

Para los ańos setenta Villegas (2002) señala que en el periodo presidencial 1974-1978 continuaron las propuestas para los pequeños negocios, se siguió con el apoyo en capacitación y formación de asociaciones empresariales y los programas se hicieron extensivos a las asociaciones. De esta manera, a partir de 1974, mediante los planes del Departamento de Planeación Nacional, se estimuló el desarrollo de las pequeñas y medianas empresas (Villegas, 2002: 83; Aristizábal, 1983). Según este autor 2002: 83), con la creación del Programa de Pequeños Proyectos del Banco Interamericano de Desarrollo (BID) en 1978, el país comienza un proyecto de expansión de dicho sector que tuvo las siguientes características: de 1970 a1974 se podría considerar de expansión; de 1974 a 1976 fue un periodo de recesión debido a la crisis petrolera mundial, y el periodo de 1976 a 1979 fue de recuperación.

En los ochenta, con el apoyo de 15 organizaciones no gubernamentales (ONG), el gobierno emprendió un estudio del sector para entender y conocer sus características. Villegas (2002) resalta que como resultado de esta iniciativa y de la crisis de mediados de los años ochenta que provocó una reducción considerable de personal de las medianas y grandes empresas, el mandatario Belisario Betancur, diseñó el Plan de Integración Nacional, con el cual se buscó darle prioridad al sector informal de la 
economía mediante crédito, capacitación técnica, asesoría administrativa, fomento a la actividad de asociación y mejoramiento de los mercados de bienes y servicios. De este proceso, Villegas (2002) destaca que sobresale el programa de Apoyo a la Microempresa (DESAP), que a partir de una organización privada, prestaba capacitación y luego se unió al BID para captar recursos para el sector microempresarial.

Durante los noventa en Colombia se adaptó el modelo neoliberal monetarista de apertura de mercados, como resultado del fracaso del modelo de sustitución de importaciones. De acuerdo con Castañeda y Cubillo (2003) y Ramírez (1998), estas nuevas condiciones obligaron a reestructurar las propuestas del gobierno a las microempresas y a formular opciones distintas de programas de apoyo a éstas en el nuevo contexto económico. Como consecuencia de lo anterior, según la Fundación Corona, se propuso una nueva política dirigida a promover y expandir las micro, pequeñas y medianas empresas con base en "aumentar la productividad de las microempresas, para lograr una mayor competitividad de los productos, mejorar su acceso al crédito, optimizar sus canales de comercialización e insertar las pequeńas unidades en nuevos mercados y, como fruto de ello, mejorar los ingresos y el nivel de vida de sus propietarios y trabajadores" (2002: 23). Como resultado de lo anterior, Kirkpatrick y Maimbo (2002) señalan que se crearon centros de desarrollo productivo y el proyecto Programas de Mercadeo dirigido a fomentar la comercialización, apoyar el proceso productivo y acceso fácil a créditos, entre otros aspectos. A finales de los años noventa las actividades crediticias de las instituciones microfinancieras (IMF) dejaron de considerarse marginales. En Colombia el esfuerzo más grande que se puede ubicar como perteneciente a esta era es el Programa de Crédito para la Microempresa, apoyado por el BID. De acuerdo con Castañeda y Fadul (2002), dicha institución comenzó su programa de pequeños proyectos en asociación con la Fundación Carvajal, pero en 1984 ya había ocho ONG comprometidas con esta actividad. Según estos autores, el programa buscaba principalmente acelerar la industrialización del país. Para Barona (2004) el concepto que prevalecía por aquel entonces era que por carencia de conocimientos y capacitación gerencial, los microempresarios tenían mucha dificultad para hacer crecer sus negocios. Esto porque el crédito se diseñó como un señuelo para atraer a este tipo de emprendedores al programa: como condición para recibir este servicio deberían participar en actividades de capacitación orientadas a desarrollar habilidades gerenciales. Como sostiene Barona (2004), a mediados de la década de los ochenta Acción Internacional comenzó a promover su metodología de crédito solidario en diferentes partes del país. Por esa misma época, señala que también se creó en el Departamento Nacional de Planeación (DNP) 
una unidad especializada cuyo propósito era dar continuidad a las políticas públicas relacionadas con el microcrédito.

A finales del siglo xx se comenzó a trabajar en la formulación de una ley para impulsar a este sector, lo que dio como resultado la promulgación de la Ley 590 en el año 2000, dictada con el fin de promover el desarrollo integral de las micro, pequeñas y medianas empresas, pues se consideró la capacidad que podían tener para generar no sólo empleo, sino también desarrollo regional e integración de los sectores económicos, entre otros. Esta ley buscaba estimular la formación de mercados competitivos, induciendo el establecimiento de un entorno institucional adecuado que emanara permanentemente políticas favorables al desarrollo y la competitividad de dichas empresas, facilitando la dotación de factores económicos, no sólo adquisición de materias primas, sino también para la formación de capital humano, asistencia para el desarrollo tecnológico y acceso a los mercados financieros internacionales (Villegas, 2002: 86). Así, se crearon dos consejos superiores, uno para la pequeña y mediana empresa y otro para la microempresa y se estableció un verdadero sistema y una organización institucional de atención al sector.

Aun con la importancia de esta Ley, en 2004 se aprobó la Ley 905. De acuerdo con Castañeda y Rivera, esta ley respecto de la anterior tenía como principales cambios en términos del marco institucional, que creaba dos sistemas en uno: 1) el Sistema Nacional de Microempresas, "conformado por los Consejos Superior de Pequeña y Mediana Empresa, el Consejo Superior de Microempresa, y por los Consejos Regionales”, y 2) el Sistema Nacional de Apoyo a las Mipymes “integrado” por nueve entes gubernamentales, "para coordinar las actividades y programas que desarrollen las Microempresas" (2004: 16-17). Estos autores también comentan que respecto a las instancias de decisión se establecía que la coordinación general de la actividad especializada hacia las microempresas que realizaron las entidades que hacían parte del "marco institucional", competía de manera exclusiva al Ministerio de Comercio, Industria y Turismo. Asimismo destacan el hecho que ordenaba al gobierno nacional reglamentar las funciones del Consejo de Microempresas siguiendo lineamientos expresos, pero no establecía qué estatus tenía ese Consejo frente a los Consejos Superiores de la Pyme y de la Microempresa. También mencionan que entre las funciones que se pedía tener en cuenta en esa reglamentación, incluía que ese Consejo "podría recomendar proyectos presentados al Fomipyme, Colciencias y el sena” (Castañeda y Rivera, 2004: 16-17). Respecto a los instrumentos de política, la Ley 905 no hacía innovaciones importantes a los instrumentos de política, sin embargo, algunos cambios introducidos en el texto de algunos artículos podían considerarse de carácter instrumental. 
Aunque se han promulgado nuevas leyes, la política pública que se viene desarrollando hacia la microempresa todavía está determinada por lo que definió la ley de 2004, por lo que se sigue adecuando la actividad de la microempresa a las nuevas condiciones de mercado y al proceso de globalización, en lo cual el mayor interés y apoyo lo reciben las pequeñas y medianas empresas, porque se consideran más competitivas. De acuerdo con Castañeda y Rivera (2004: 29), en las dos normas, así como en el ámbito político-administrativo en el que han tenido y tendrán sus efectos, persiste un retroceso en el desarrollo de normativa de la institucionalidad pública y en la función que cumple en la evolución de las relaciones entre el Estado y la sociedad civil colombiana en sus actos a favor del desarrollo de ese amplio y estratégico sector conformado por las micro, las pequeñas y las medianas empresas.

\subsection{El caso mexicano}

El proceso de industrialización de México comenzó en la década de los cuarenta, el cual pasó por diversos modelos económicos de desarrollo proteccionistas, en cuyas etapas proliferaron las micro, pequeńas y medianas empresas, pero desarticuladas de la gran industria y dispersas en el ámbito regional, específicamente desarrollando actividades tradicionales.

Durante el periodo 1945-1979, la política de industrialización del país se basó en la estrategia de sustitución de importaciones, utilizando medidas proteccionistas para evitar la competencia del exterior. Arboleda (1997) comenta que en ese periodo la expansión de la demanda interna en México hacía más rentables las ventas al mercado interno que a la exportación. Este modelo de protección industrial funcionó en sus primeras etapas, en particular en los bienes de consumo durables y no durables; posteriormente, señala el autor, este avance se vio limitado cuando se requirió la producción de bienes intermedios y de capital con cierto nivel de sofisticación. Aquí fue donde se careció de un desarrollo tecnológico y de la integración de una pequeña y mediana empresa con los sectores avanzados. En este contexto, señala Arboleda, además de que no hubo un crecimiento industrial soportado en la vía tecnológica y que no se contó con un esquema de especialización manufacturera, la política industrial no fue lo suficientemente capaz de aprovechar a las micro, pequeñas y medianas empresas como proveedoras en el ámbito nacional de las grandes empresas, lo que limitó su desarrollo y participación industrial en sectores tradicionales de mayor integración tecnológica.

En los años ochenta nace la verdadera preocupación por la supervivencia de este tipo de empresas, ya que el surgimiento de la competencia como un nuevo elemento de la liberalización económica en el mercado 
podía provocar su desaparición. Así surge (García y Paredes, 2001) una serie de normativas y programas dirigidos a apoyar específicamente a las micro, pequeñas y medianas empresas. A finales de los ańos ochenta, con la finalidad de que los apoyos se canalizaran principalmente a la microindustria, surge la Ley Federal para el Fomento de la Microindustria, con el objetivo de "fomentar el desarrollo de la microindustria mediante el otorgamiento de apoyos fiscales, financieros, de mercado y de asistencia técnica, así como facilitar la constitución de las mismas simplificando trámites administrativos" (García y Paredes, 2001: 45). Esta ley constituyó uno de los primeros esfuerzos para apoyar a la microindustria, así se comenzó a reconocer la importancia de este subsector como el nuevo motor del desarrollo económico y la necesidad de normarle e impulsar su crecimiento.

A principios de los años noventa, al profundizarse el proceso de apertura de la economía mexicana, surge el reto de lograr una modernización acelerada de todos los sectores, sobre todo el industrial. Con el Plan Nacional de Desarrollo (1989-1994), que enmarca las acciones del gobierno de entonces, se comienza a plantear como estrategia fundamental la modernización económica de todas las actividades productivas y de servicios del país, para lo cual se establecieron lineamientos generales (Arboleda, 1997). Como resultado de dicho plan, se elaboraron y decretaron programas dirigidos a promover el desarrollo de diversos sectores. García y Paredes refieren que en diciembre de 1991 se decretó la creación de Empresas de Solidaridad, órgano desconcentrado de la Secretaría de Desarrollo Social (Sedesol), con el objetivo de "impulsar proyectos productivos de los grupos sociales que vivían en condiciones de pobreza, para fortalecer su autonomía económica, con el suministro de capital de riesgo temporal y el financiamiento a través de fondos de garantía en los estados, dirigidos a crear empresas de campesinos y para campesinos, así como de los grupos populares urbanos Respecto a la elegibilidad de los proyectos". Empresas de Solidaridad apoyaba a quienes eran técnica, económica y financieramente viables. Sin embargo, una de las tareas más difíciles era evaluar proyectos que solicitaban financiamiento, ya que se había tenido que conciliar el concepto de rentabilidad con el de viabilidad, principalmente organizativa y social (2001: 46). A diferencia de otras instituciones que buscaban colocar sus recursos donde más garantías y rentabilidad encontraban, en este proyecto (García y Paredes, 2001) se buscó trabajar más cerca de los mínimos de rentabilidad, propios de la empresa social, pero con énfasis en la viabilidad social y organizativa del grupo, aunque no siempre se alcanzó el objetivo.

El gobierno del presidente Ernesto Zedillo fue una continuación y profundización de la política hacia la industria y el comercio exterior 
iniciada en 1988. En 1995 la crisis condujo a que el PIB manufacturero cayera cinco puntos y a que la banca se sacudiera con la deuda impagable de los particulares, debido a la elevación de las tasas de interés. Esta situación, de acuerdo con Garrido (2002), tuvo un efecto muy grave en las empresas en general, pero sobre todo en las pequeñas y medianas (más que en las micro que siempre tienen mayor tolerancia, en especial cuando están en la economía informal). El autor comenta que una investigación del Centro de Estudios Económicos de la Cámara Nacional de la Industria de la Transformación (Canacintra) mostró que en abril de 1995 se habían cerrado 5,856 establecimientos, sobre todo en las ramas de productos metálicos, vestido, cuero y calzado.

A mediados de los noventa, en medio de la crisis, se creó el Consejo Nacional de las Micro, Pequeñas y Medianas Empresas, cuyo objetivo era establecer políticas e instrumentos para aumentar la eficiencia y calidad, así como fortalecer las cadenas productivas para vincular a las pequeñas empresas con las de mayor tamaño. De acuerdo con Donato (2003), formaban parte de este consejo diversas dependencias del gobierno, instituciones de la banca de desarrollo y organizaciones privadas representativas de las pequeñas y medianas empresas. En 1996 se instituyó la Comisión Intersecretarial de Política Industrial (CIPI), integrada por las secretarías de Comercio y Fomento Industrial (Secofi), la de Agricultura y Ganadería (Sagar), la de Hacienda y Crédito Público (sHCP), la de Controlaría y Desarrollo Administrativo (Secodam), el Consejo Nacional de Ciencia y Tecnología (Conacyt), Nacional Financiera (Nafin) y el Banco de Comercio Exterior (Bancomext), con el propósito de mejorar la coordinación de las acciones en materia de apoyo a la industria nacional (Donato, 2003; García y Paredes 2001; De Maria, 2002). En 1998, la CIPI realizó un inventario de programas de apoyo del gobierno a empresas del país, se encontraron 131 programas en las instituciones que conformaban esta comisión y que apoyaban a las empresas.

En 1997 se creó el programa Compite con el objetivo de incrementar la productividad de las empresas manufactureras. Por medio de este programa, refiere De Maria (2002), se impartieron talleres teórico-prácticos en las instalaciones de las empresas participantes, para dar asistencia técnica a las micro y pequeñas empresas para optimizar sus procesos productivos y mejorar el aprovechamiento de sus recursos humanos y de capital. También apareció el programa de implementación de un sistema de calidad en las micro, pequeñas y medianas empresas en el cual participaban la Fundación Mexicana para la Innovación y Transferencia de Tecnología en la Pequeña y Mediana Empresa (Funtec), Nafin y otras organizaciones vinculadas al desarrollo de la calidad. El objetivo del programa era promover una cultura de aseguramiento de la calidad en este tipo de empresas, a 
través del establecimiento de sistemas de calidad ISO 9000 (De Maria, 2002: 5). Un aspecto importante que señala este autor es que hasta finales del año 2000 se rehuyó en relación con las microempresas la definición de un programa integral para apoyar a este sector, a pesar que los industriales de la Concamin y la Canacintra insistieron en que se hiciera algo, por lo menos similar a lo que existe en el caso de los principales socios comerciales: Estados Unidos, Canadá y los países de la Unión Europea.

A principios del siglo XxI, durante el gobierno de Vicente Fox, vuelve a aparecer el interés por promover e impulsar la microempresa. Mediante la Secretaría de Economía se creó el Programa de Financiamiento del Microempresario -mejor conocido como microchangarros-, y se dirigió a los sectores más desprotegidos del país. Se formó un fideicomiso, es decir, una bolsa de dinero que servía para dar líneas de crédito a instituciones financieras que serían las encargadas de repartir los recursos a la población solicitante. La forma en que operaron los microcréditos fue cíclica: se realizó un préstamo inicial para dar otro mayor en cuanto se pagara la primera deuda; de esta manera se podía aspirar al crecimiento (Sedesol, 1999). Así, hubo zonas donde se empezó con préstamos de 500 pesos y otras con 1,000 y 2,000 pesos, según las necesidades del lugar, y de ahí se suponía que el préstamo podría crecer en ciclos hasta un máximo de 20,000 o 30,000 pesos. Esta propuesta, al igual que las otras planteadas, se quedaron en buenos propósitos, pues fueron pocos los resultados.

\section{Características sociodemográficas}

En los últimos años el crecimiento de la microempresa en Colombia y México ha sido de gran importancia, situación que ha dado lugar a una mayor participación de personas en este sector de la economía. De acuerdo con el Departamento Nacional de Estadística (DANE), y el Departamento de Planeación Nacional, en 1990 en Colombia había más de 258,000 microempresas que empleaban alrededor de 1.7 millones de personas; en 2003 el número de microempresas en el país creció de manera importante: alcanzó un total de 1’328,000 establecimientos que empleaban a más de 2.5 millones de personas. En el caso mexicano el número de establecimientos ha sido significativamente mayor, pues según datos del INEGI, en el año 1990 las microempresas empleaban alrededor de 8.5 millones de personas y para 2003 aumentó a más de 10.7 millones de trabajadores. Veamos entonces las similitudes y diferencias de las características sociodemográficas de las microempresas en ambos países, teniendo en consideración aspectos como población por sexo, escolaridad y edad. 


\subsection{Participación por sexo}

El número de establecimientos presenta una marcada diferencia entre los dos países, la cual se mantiene durante el periodo estudiado a pesar del aumento que se ha dado. La cantidad de microempresas mexicanas supera con mucho a las colombianas. Sin embargo, la distribución porcentual de hombres y mujeres en este sector de la economía presenta características muy similares, sobresale una mayor participación de los hombres tanto en Colombia como en México. No obstante, en el caso colombiano poco más de $50 \%$ son hombres, mientras que en México en todos los años los hombres representan más de $60 \%$ de la distribución por sexo de los microempresarios (gráfica I).

De acuerdo cn algunos datos (BID, 2004; INEGI, 2004), la población masculina de la microempresa colombiana pasó de 57.7\% (1’038,073) en 1990 , a representar $53.5 \%\left(1^{\prime} 350,558\right)$ en 2003; por su parte, la femenina se incrementó de forma importante al pasar de $42.3 \%(761,014)$ a $46.5 \%\left(1^{\prime} 173,849\right)$. En el caso mexicano la presencia masculina pasó de $63.1 \%\left(5^{\prime} 373,648\right)$ a $66 \%\left(7^{\prime} 119,817\right)$ y la población femenina vinculada a la microempresa pasó de $36.9\left(3^{\prime} 142,435\right)$ a 34\% (3’667,784) en este periodo.

\section{Gráfica I}

Distribución de la participación de microempresarios en Colombia y México por sexo, 1990-2003

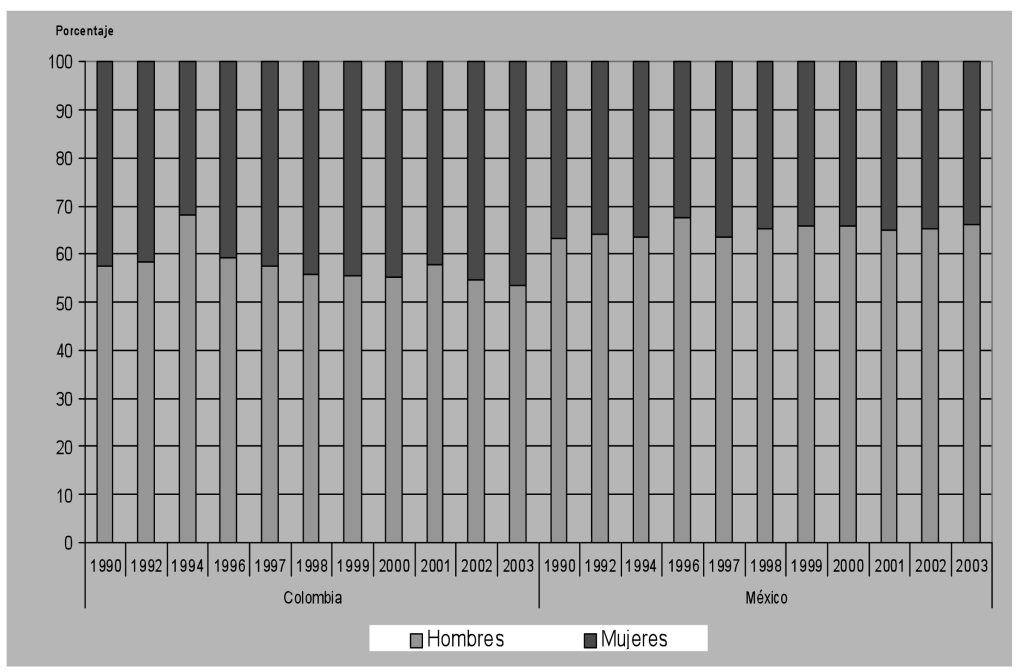

Fuente: Elaboración propia a partir de datos del BID (2004) para el caso colombiano y del INEGI (2004) para México. 
Aunque en términos generales se evidencia para ambos países una mayor presencia de hombres vinculados con la microempresa, sobresale el hecho de que durante el periodo analizado en Colombia se ha dado una mayor participación femenina en este sector de la economía, situación que no se refleja en el caso mexicano, pues según los datos se presenta una ligera disminución porcentual en la participación de la mujer en los últimos años (gráfica I).

Es importante señalar que este aumento de la presencia femenina en la microempresa en la segunda mitad de la década de los noventa en Colombia, como en otros países de América Latina, tiene que ver con el hecho de que a partir de las conferencias de El Cairo en 1994 y de China en 1995, se hizo un planteamiento a favor de una mayor participación social y económica de la mujer. En ese sentido, se consideró la actividad de la microempresa una buena alternativa para favorecer el empoderamiento social de la mujer, de ahí la política de promoción de la microempresa desde estas conferencias en general, y por el BID en particular, ya que se partía de considerar la participación femenina como un determinante de éxito personal, así como del sector.

$\mathrm{Si}$ bien es cierto que los hombres y las mujeres trabajan en la microempresa, su situación en ambos países difiere en muchos aspectos, por ejemplo, en cuanto a horas y tipos de trabajo y también en relación con la remuneración. La fuerza de trabajo femenina se concentra en el pequeño comercio y servicios, donde se necesita sólo un pequeño capital y bajos niveles de capacitación profesional para iniciar una actividad. En el sector del comercio las mujeres se dedican especialmente a pequeñas actividades por cuenta propia, como la venta de alimentos; mientras que los comerciantes del sexo masculino tienden a dedicarse a actividades en mayor escala y que no tienen que ver con la alimentación. Tales circunstancias colocan a las mujeres a cargo de estas microempresas en condiciones más difíciles que los hombres, pues sus actividades no sólo tienden a la informalidad y a generar menores recursos, sino que además su esperanza de sobrevivencia es más corta que otras actividades.

En el sector de la microempresa las mujeres trabajan principalmente en régimen de subcontratación o llevan a cabo tareas no remuneradas en el ámbito familiar. Los hombres, por su parte, normalmente desempeñan la función de subcontratistas o se dedican a actividades como la recolección de materias primas y a la entrega de productos finales. No es tan común verlos trabajar en la casa, como ocurre con las mujeres. En los sectores de la construcción, el transporte y los servicios, a las mujeres sobre todo se les contrata como trabajadoras ocasionales. 


\section{Gráfica II \\ Escolaridad de las personas vinculadas con la microempresa en Colombia, 1990-2003}

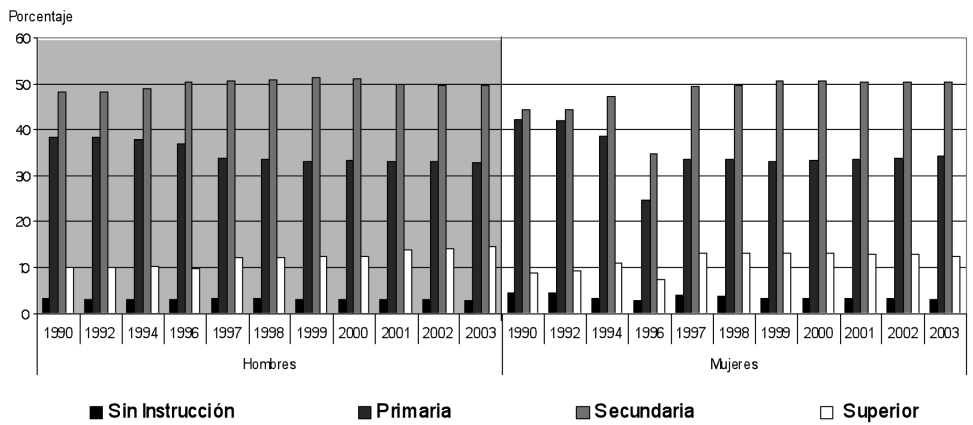

Fuente: Elaboración propia a partir de datos del BID (2004).

\subsection{Escolaridad}

En lo referente al nivel de escolaridad de las personas que participan en la microempresa, se encontró, tanto para Colombia como para México, que a diferencia de lo que se tiende a considerar de que en este sector prevalecen bajos niveles de estudios, el grado de escolaridad es relativamente alto. En el caso de Colombia durante el periodo 1990-2003, se podría afirmar que no se presentaron mayores diferencias en la escolaridad tanto en hombres como en mujeres. Más de $40 \%$ de las personas que participan en la microempresa tienen estudios de secundaria, y en el caso de los hombres, casi la mitad dice tener este nivel de estudios. Por su parte, las personas con educación primaria también representan un sector importante, pues en el caso de los hombres más de 30\% dijo haberla cursado.

En el caso de las mujeres colombianas que pertenecen a este sector de la economía, también sobresalen aquéllas cuyo máximo nivel de estudios es primaria. En los primeros años del periodo analizado (1990-1992) se encontró que más de $40 \%$ de ellas había concluido este ciclo, sin embargo, la cantidad de mujeres con educación primaria ha venido disminuyendo y a lo largo del tiempo comenzó a aumentar el porcentaje de mujeres con secundaria. Esta tendencia se hace evidente también en el caso de los hombres colombianos (gráfica II ). Las personas con formación técnica-superior representan un número menor a los de primaria y secundaria, pero aun así es importante en los colombianos vinculados con la microempresa, situación que corrobora que el nivel de educación en este sector de la economía es relativamente alto. Un aspecto significativo a tener en cuenta es que en el nivel superior no se presentan grandes dife- 


\section{Gráfica III \\ Escolaridad de las personas vinculadas con la microempresa en México, 1990-2003}

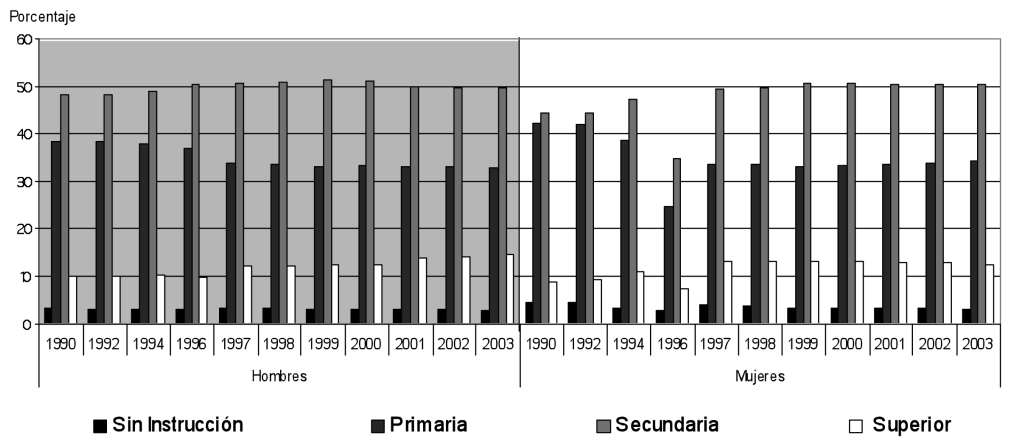

Fuente: Elaboración propia a partir de datos del INEGI (2004).

rencias entre hombres y mujeres y, además, que a partir de 1997 comienza a darse un ligero incremento en la cantidad de personas con este grado educativo. Las personas sin instrucción son las que representan la minoría, en promedio constituyen alrededor de 3\% de la población vinculada con la microempresa en Colombia (gráfica II). En general, se podría señalar que en el sector de la microempresa colombiana no se encuentra la población menos educada, sino que guarda un patrón similar a las características educativas del total de la población.

En cuanto a México, la escolaridad de las personas de este sector presenta un patrón diferente al del caso colombiano. El nivel de secundaria sobresale en el conjunto de la población vinculada con este sector de la economía, sin embargo, existen grandes diferencias entre hombres y mujeres, pues más de la mitad de los hombres en el periodo analizado alcanzan alrededor de $40 \%$ y a partir de 1998 este número se incrementa de manera importante, lo que hace menos notoria la diferencia entre ambos sexos para el final del periodo (gráfica III). Aquí conviene resaltar lo que señala el INEgi para el año 2003, donde se encontró que los hombres reportaron en promedio siete años de escolaridad y las mujeres 6.6 años aprobados.

Respecto al nivel primaria, en el caso mexicano no se evidencian grandes diferencias entre hombres y mujeres, alrededor de $20 \%$ de las personas vinculadas con la microempresa alcanzaron este nivel de estudios. La tendencia a lo largo del tiempo muestra que cada vez es menor el porcentaje de personas con primaria y mayor el de quienes cursaron secundaria. Debe señalarse que una cantidad importante de la población 
relacionada con este sector de la economía dice tener estudios superiores. En ambos sexos éste sobrepasa 10\% de la población. En este grado de instrucción sí se presentan diferencias, el número de hombres en promedio durante todo el periodo se mantiene alrededor de $15 \%$, mientras que en el caso de las mujeres está ligeramente por encima de $10 \%$, mismo que decrece en algunos ańos al final del periodo estudiado. Ciertamente, a diferencia de los otros niveles de escolaridad, en las personas con estudios superiores no se evidencia una tendencia clara en este periodo (gráfica III). Pese a que las personas vinculadas con la microempresa en México presentan un nivel educativo relativamente alto, existe un grupo muy importante que dijo no tener instrucción, situación que se hace más evidente en el caso de las mujeres, donde más de $10 \%$ no tenía instrucción, y en los primeros ańos del periodo analizado este porcentaje es relativamente superior: en 1990 fue de 20.1, en 1991 de 19 y en 1992 de $18 \%$ (gráfica III).

En promedio, en el año 2003 los hombres contaban con siete años de estudio, cerca de medio año más que las mujeres, cuya escolaridad fue de 6.6 ańos. Por grupos de edad, hasta los 29 años, las mujeres contaban con más años de escolaridad que los hombres, sin embargo a partir de los 30 años la escolaridad de los hombres era superior a la de las mujeres. Dicho comportamiento obedecía al hecho de que las generaciones jóvenes contaban con una instrucción escolar mayor comparada con la de las generaciones de las personas de edad avanzada, y por el otro, a la presencia de mujeres jóvenes con niveles de escolaridad superior a la de los hombres en ocupaciones de la microempresa. En el caso de los hijos e hijas de familia, contaban con un promedio de escolaridad superior a 7.9 y 8.2 ańos, respectivamente, comparado con el de sus padres, en este caso de los jefes de hogar y de las cónyuges, los primeros reportaron 6.5 años de estudio y las segundas, 6.2 ańos (INEGI, 2004).

\subsection{Edad}

El análisis de la característica de edad permite ver para el caso colombiano que la mayor proporción de población en este sector estaba entre los 30 y 39 ańos, seguido por el grupo de 20 a 29 ańos. En cuanto al sexo, la proporción de hombres de 30 a 39 ańos siempre ha estado por encima de $25 \%$, presentando una tendencia creciente en los años más recientes, mientras que la proporción de hombres de 20 a 29 ańos ha venido decreciendo durante el periodo estudiado, lo que hace suponer que el grupo de hombres jóvenes ha perdido importancia en la microempresa. Por su parte, las mujeres de 20 a 29 ańos en el periodo 1990-1994 estuvo por encima de 30\%, y descendió de manera importante hasta representar en 


\section{Gráfica IV \\ Edad de las personas vinculadas con la microempresa en Colombia, 1990-2003}

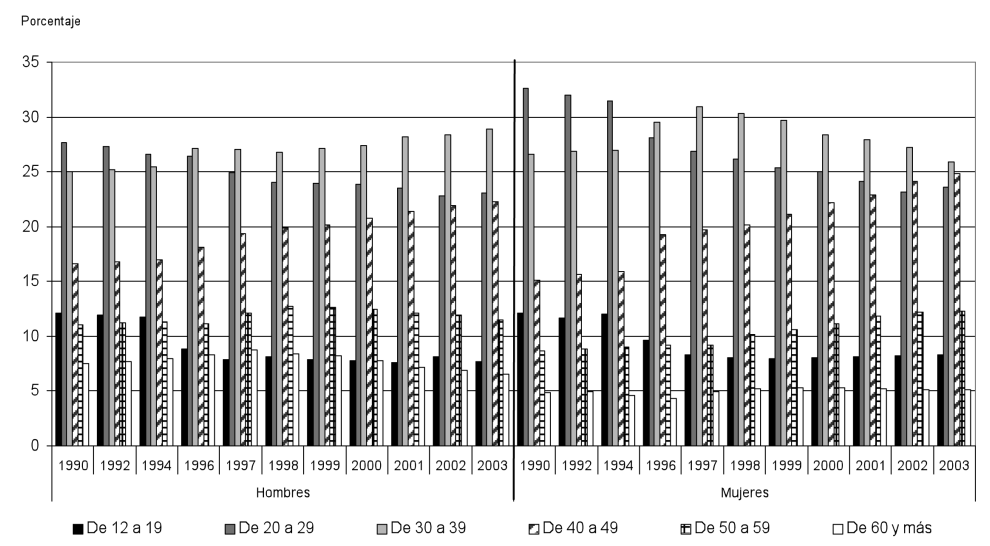

Fuente: Elaboración propia a partir de datos del BID (2004).

el año 2003 el 23.6\%. Al igual que los hombres, hay un mayor número de mujeres de 30 a 39 años vinculadas con la microempresa (gráfica IV).

Un aspecto que llama la atención es la tendencia creciente en la participación de personas en la microempresa del grupo de edad 40 a 49 y 50 a 59 años, siendo más notoria en el primer grupo. Esta situación se hace evidente tanto en hombres como en mujeres, pues en cuanto a ellas, el porcentaje del grupo 40 a 49 años en 1990 fue de 15.2 y en 2003 aumentó a $24.8 \%$. En el caso de las personas mayores de 60 años los datos muestran una participación muy importante de este grupo de la población, más evidente en el caso de los hombres. En cuanto a los menores de 19 ańos su participación en la microempresa ha venido decreciendo y no parece ser lo relevante que se tiende a suponer en relación con el hecho de que es un grupo de edad que aparece como ayudantes familiares.

En términos generales se observa que en cuanto a las diferencias por sexo de los microempresarios en Colombia, en el caso de las mujeres tiende a prevalecer una mayor presencia en edades más jóvenes en comparación con los hombres. El hecho de que la mayor parte de la microempresa estuviese compuesta por adultos en plena etapa productiva, demuestra su dinámica en la generación de empleo, ante la imposibilidad del sector formal de hacerlo. Pero habría que llamar la atención sobre la calidad del empleo que se está generando y ello amerita mayor investigación al respecto.

En México, los ocupados en este sector se caracterizan porque la mayoría está entre los 20 y 29 años de edad, sin embargo, se presentan algu- 


\section{Gráfica $v$}

Edad de las personas vinculadas con la microempresa en México, 1990-2003

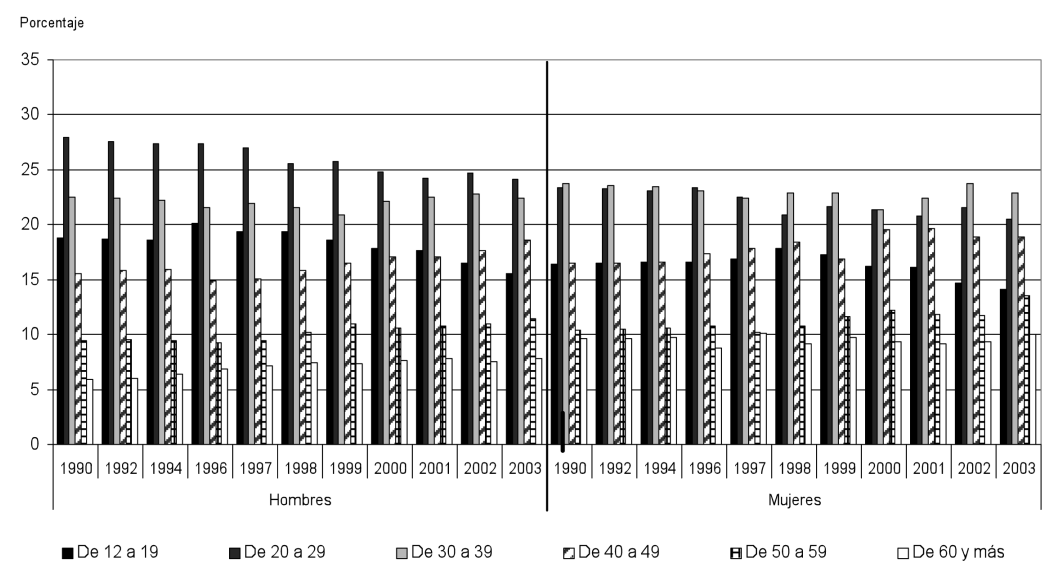

Fuente: Elaboración propia a partir de datos del INEGI (2004).

nas diferencias entre hombres y mujeres, pues el número de hombres de 20 a 29 años de 1990 a 1999 estuvo por encima de 25\%, claro está que ha presentado un descenso importante, no obstante sigue siendo el grupo que predomina. En el caso de las mujeres, aunque un alto porcentaje está en edades de 20 a 29 ańos, los datos muestran que predominan en orden de importancia quienes se encuentran en el grupo de 30 a 39 ańos.

Dicho comportamiento parece indicar que son principalmente las mujeres que han terminado su ciclo reproductivo y la crianza de sus hijos las que se insertan en mayor medida en el sector de la microempresa, probablemente porque, al igual que los hombres, a partir de cierta edad enfrentan más dificultades para encontrar ocupación en el sector estructurado de la economía. El anterior supuesto se relaciona con el importante incremento que se dio durante el periodo analizado de las personas de 40 a 49 y de 50 a 59 años de edad en la microempresa mexicana. En 1990, del total de personas relacionadas con la microempresa, $15.5 \%$ se encontraba entre los 40-49 años y en 2003 este porcentaje se incrementó a 18.6, en el caso de las mujeres la tendencia es la misma. De igual forma, las personas mayores de 60 años han presentado una tendencia creciente en la participación en este sector de la economía (gráfica v).

\section{A manera de conclusión}

Cuando se analiza la política pública dirigida a la microempresa, se observa que si bien no es reciente, presenta carencias notorias en los aspec- 
tos normativos y en los programas desarrollados. Las deficiencias de las políticas públicas que se han diseñado para las microempresas son de diversa índole y varían según las circunstancias económicas, políticas y sociales en América Latina. Tales políticas, que en un comienzo se pensaron con un carácter asistencialista y con una intención de carácter ideológico, se fueron transformando a una concepción más de carácter de sostenibilidad económica enfocadas a promover prácticas competitivas en los ámbitos local y regional, enmarcadas en el contexto de la globalización, pero cada vez menos a favor de los sectores desfavorecidos. En Colombia, por ejemplo, el gobierno no ha tenido una política efectiva para apoyar a este sector y los créditos que ha ofrecido resultan irrisorios y ha tenido un mayor efecto la legalización y formalización de la actividad que el beneficio final que se recibe. En México, por su parte, si bien es cierto que aumentó el nivel de coordinación institucional y la incorporación de criterios comunes para el diseño y evaluación de iniciativas de diferentes organizaciones, ello no se ha manifestado en un beneficio real para los microempresarios. En ambos países otro problema es la política social hacia la microempresa, pues su fundamento teórico-filosófico no refleja una normatividad que se oriente a la atención de todos los individuos -en particular a los que están en la peor situación social-, sino a los trabajadores del campo o la ciudad. Por tanto, falta una mayor focalización en los diversos contextos donde se desarrolla la microempresa.

En la medida que la microempresa es parte fundamental para la generación de empleo, a futuro debe existir mayor compromiso de los gobiernos en materia de política social de apoyo a los microempresarios que garantice su sostenibilidad, antes que la posición cuantitativa que busca tener más microempresas, cuando lo que se requiere es su permanencia en el mercado. Hay que buscar nuevas opciones de financiamiento, que sean más reales y con mejores condiciones. Ahora bien, vista la microempresa en relación con la pobreza y el desarrollo, una de las principales recomendaciones de política a la microempresa es que debe ser formulada más en función de los microempresarios y menos en las directrices macroeconómicas. Es indudable que se requiere un mayor conocimiento de los microempresarios de acuerdo con sus realidades socioeconómicas, lo que facilitaría una política más focalizada y más efectiva. Es aquí donde se observan los mayores retos, en la medida que la política prioriza el interés económico global, y por ende de unos cuantos, sobre la dinámica económica local desde la cual se quiere trabajar en función del desarrollo, por lo que la microempresa queda supeditada a intereses macroeconómicos y con ello la idea de desarrollo que se pretende deja de ser una propuesta local. 
Las características en materia de política pública hacia la microempresa y en términos sociodemográficos que presentan los dos países analizados, son interesantes no sólo por las semejanzas y diferencias que presentan entre sí, sino que son una muestra de los importantes cambios que están ocurriendo en un sector de vital importancia para la economía latinoamericana y sobre lo cual tenemos un gran desconocimiento, de ahí la intención del presente artículo para contribuir en esa dirección y sugerir la necesidad de más estudios comparativos para otros países de la región.

\section{Bibliografía}

Aristizábal-Castaño, Roberto (1983), "Los programas de desarrollo de microempresas: una estrategia para el desarrollo", Revista Medellín, 3, Medellín, pp. 6-7.

Arboleda, José Ubernel (1997), "Una misión posible: políticas y programas de apoyo a la microempresa en Colombia”, Departamento Nacional de Planeación, Bogotá.

Barona, Bernardo (2004), "Microcrédito en Colombia", Estudios Gerenciales, 90, Universidad ICESI, Bogotá, pp. 79-102.

BID (Banco Interamericano de Desarrollo) (2004), Macroimpacto con microdinero. 25 años de apoyo a la microempresa. Somos más que un Banco, BID, Washington.

Castañeda, Alberto y Rafael Cubillo (2003), "Situación de la microempresa en Colombia, programas de apoyo y acceso al crédito", Documento de Trabajo 10, Fundación Corona-Fundación Ford, Bogotá.

Castañeda, Alberto y Mario Fadul (2002), "Globalización y crisis económica. Incidencia en la financiación de unidades de pequeña escala”, Fundación Corona-Fundación Ford, Bogotá.

Castañeda, Alberto y Carlos Fernando Rivera (2004), "Ley 905 de 2004. Alcances y limitaciones de la política de apoyo microempresarial", en Fondo privado para el estudio de la pequeña y mediana empresas, Fundación Corona, Bogotá, pp. 16-17.

Donato, Vicente, Christian M. Haedo y Sara Novaro (2003), "Propuesta metodológica para un observatorio latinoamericano de la 
pequeña y mediana empresa. Resultados de la prueba piloto Argentina-México", Documento de trabajo, BID, Washington.

Fundación Corona-Fundación Ford (2002), "Situación de la microempresa en Colombia: programas de apoyo y acceso al crédito", Documento de Trabajo 10, Fundación Corona-Fundación Ford, Bogotá.

García, Gilberto y Víctor Paredes (2001), Programas de apoyo a las micro, pequeñas y medianas empresas en México, 1995-2000, CEPAL-ECLAC, Santiago de Chile.

Garrido, Carlos (2002), "La pequeña y mediana empresa manufacturera en México", en Wilson Pérez y Giovanni Stumpo (coords.), Pequeñas y medianas empresas industriales en América Latina y el Caribe, Siglo XXI, México, pp. 302-356.

INEGI (Instituto Nacional de Estadística, Geografía e Informática) (2004), La ocupación en el sector no estructurado en México, 1995-2003, INEGI, México.

Kirkpatrick, Colin y Samuel Munzele Maimbo (2002), "The Implications of the Evolving Microfinance Agenda for Regulatory and Supervisory Policy", Development Policy Review, 20 (3), Wiley-Blackwell Press, Washington, pp. 293-304.

María-y Campos, Mauricio de (2002), Pequeñas y medianas empresas industriales y política tecnológica: el caso mexicano en las tres últimas décadas, CePal-eclac, Santiago de Chile.

Ramírez-Guerrero, Jaime (1998), El Plan Nacional para el Desarrollo de la Microempresa (PNDM) en Colombia. Una evaluación desde la perspectiva de su desarrollo institucional, Organización Internacional del Trabajo, Bogotá.

Sedesol (Secretaría de Desarrollo Social) (1999), "Resultados de los rincipales programas 1995-1999. Gobierno de México", <http:// sedesol.gob.mx/desreg/derpro.htm>, 14 de mayo de 2001.

Villegas Ángel, Luis Felipe (2002), Micro, pequeña y mediana empresa. Pasado y presente, Marco Institucional vigente sistema jurídiconormativo, Sincelejo, Bogotá. 
Recibido: 25 de noviembre de 2008.

Reenviado: 29 de julio de 2010. Aceptado: 27 de septiembre de 2010.

Fernando Neira-Orjuela. Es doctor en población por el Colegio de México. Actualmente es investigador nivel i en el Sistema Nacional de Investigadores (SNI) y se desempeña como investigador de tiempo completo en el Centro de Investigaciones sobre América Latina y el Caribe (CIALC) de la Universidad Nacional Autónoma de México. Sus líneas de investigación son: políticas públicas y desarrollo, migración latinoamericana y remesas y desarrollo. Entre sus publicaciones destacan: "La necesidad de una nueva agenda de política hacia la microempresa latinoamericana", Revista Universidad Javeriana, 744 (144), Universidad Javeriana, Bogotá, pp. 44-51 (2008); "Las microempresas como mecanismo de integración política y económica en América Latina", Convergencias y Divergencias, unam, México, pp. 209-228 (2007); "México y Cuba: una mirada actual de las relaciones económicas", Relaciones México-Cuba 1950-2006: historias y perspectivas. Cátedra Extraordinaria "José Martí" 30 y 31 de octubre de 2006, Cátedra "Benito Juárez", 11 y 12 de diciembre de 2006, unam, México, pp. 157-184 (2007); "Participación laboral y autonomía femenina en un contexto de agricultura urbana”, Estudios Demográficos, 20, 3 (60), El Colegio de México, México, pp. 533-567 (2005). 